\title{
Study on water resources optimal regulation of inter-basin water transfer project
}

\author{
Ma Jigang ${ }^{1}$ Wang Haofang ${ }^{* 2}$ Zhao Libin ${ }^{1}$ Wei Song ${ }^{1}$ \\ ${ }^{1}$ Shandong province bureau of Jiaodong water diversion, Jinan 250100, China \\ 2. School of Civil Engineering, Shandong University, Jinan 250061, China
}

\begin{abstract}
Water resources optimal regulation is an important means to mitigate the shortage of water resources and promote social and economic sustainable development in regions or watershed. With the rapid development of urban population and industrial and agricultural production in recent years, the shortage of water is becoming more and more serious in Jiaodong area. The four regions with serious water shortage including Weifang, Qingdao, Yantai and Weihai in Jiaodong area are the typical research areas. In combination with the water transfer project of Yellow river to Qingdao and the south-to-north water transfer project, the water diversion is carried out to alleviate the contradiction between water supply and demand of Jiaodong area. The year of 2014 deemed as the base year and the years of 2020 and 2025 are the planning years. Based on the supply and demand analysis of water resources, an optimal regulation model is built with the minimum total water shortage considering the constraints of water supply capacity of project, water distribution capacity and minimum water supply of bleeds and so on. The optimal regulation schemes are obtained by solution model using MATLAB programming. The results show that water shortage rate of the four cities decreases significantly in annual regulation. For different planning years, guarantee rate of $50 \%, 75 \%$ and $95 \%$, the total water shortage rate will be reduced by $15.35 \%, 15.75 \%$ and $16.85 \%$ respectively in 2020, and in 2025the total water shortage rate will be reduced by $13.27 \%, 13.26 \%$ and $14.19 \%$ respectively. Therefore the water resources optimal regulation of inter-basin water transfer project can effectively mitigate water scarcity and the contradiction between water supply and demand in Jiaodong area.
\end{abstract}

\section{Introduction}

Optimal regulation of water resources is an important means to relieve water shortage and promote sustainable development of social economy. With social and economic development and population growth in Jiaodong area, the contradiction between water supply and demand has become increasingly prominent. Therefore, water transfer across river basins is one of the important means to solve the problem of water shortage in the area

In foreign countries, the earliest cross-basin water transfer project can be traced back to ancient Egypt 4400 years ago, from the Nile to the southern part of the Ethiopian plateau. After the founding of the People's Republic of China, China successively built a number of water diversion projects, such as the Guangdong Dongshen Water Diversion Project, Water Diversion Project from Luanhe River to Tianjin, Water Diversion Project fromYellow Rive to Qingdao, and the South-to-North Water Diversion Project. In order to realize the optimal scheduling of water resources across river basin, different optimization scheduling methods are needed. Commonly optimization methods include linear programming ${ }^{[1-2]}$, nonlinear programming ${ }^{[3]}$, dynamic programming ${ }^{[4]}$, stochastic programming ${ }^{[5]}$, multi-objective programming ${ }^{[6-7]}$ and so on.

This paper takes the Jiaodong water transfer project as the research object. Under the existing engineering conditions, according to different water inflow conditions, the linear programming method is used to optimize the scheduling of the Yellow River water and the Yangtze River water to provide decision support for operation management.

\section{Overview of Jiaodong water transfer project}

Shandong Jiaodong Water Transfer Project is a large-scale water transfer project cross basins and over long distance. It is a basic, strategic and public welfare project to realize the optimal allocation of water

*Corresponding author : whf29@sdu.edu.cn, jiaoddsjzgb@163.com 
resources in Shandong Province and guarantee water use in the Jiaodong area. It includes the Yellow River Diversion Project and Jiaodong. Regional Yellow River Water Transfer Project ${ }^{[8]}$. The Jiaodong Water Transfer Project of Shandong Province is an important part of the National South-North Water Transfer Project. It channels the water from the Yellow River in Binzhou City down to Jihongtan Reservoir in Qingdao and Mishan Reservoir in Weihai, involving 6 cities of Binzhou, Dongying, Weifang, Yantai, Weihai and Qingdao. The city, together with other projects in the Shandong Reach of the East Route of the South-to-North Water Diversion Project, formed a "T"-shaped water transfer artery in the north-south and east-western of Shandong province ${ }^{[8]}$. The Jiaodong water transfer project realized the joint regulation of the Yangtze River water, the Yellow River water and the local water, thus alleviating the contradiction between water supply and demand in the Jiaodong area. The Jiaodong water transfer project route map is shown in Figure 1.

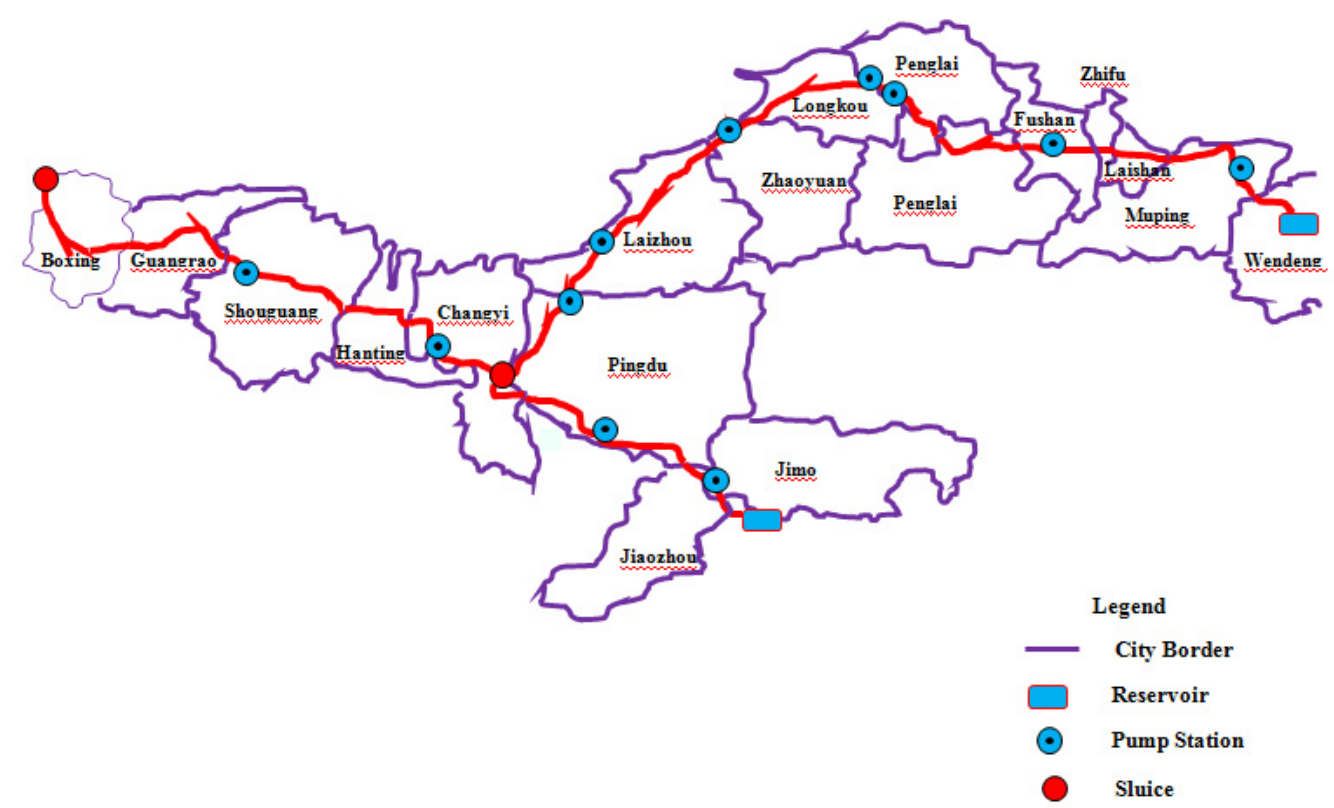

Figure 1 Jiaodong water transfer project route map

In this paper, the four cities of Weifang, Qingdao, Yantai and Weihai in the Jiaodong area,

where water shortage is more serious, are the research areas, with 2014 as the base year and 2020 and 2025 as the planning years. Through the analysis of supply and demand balance in the study area, the total amount of water shortage in the base year and the planning year of the four cities under different guarantee rates is obtained, and the water supply index (Yellow River water, Yangtze River water) of the four cities is considered to determine the water quantity that can be regulated. According to Jiaodong Water Transfer Project Status, with the minimum total water shortage in the study area as the scheduling target, considering the constraints of minimum water demand of bleeders, carrying capacity and water balance of canal and water delivery efficiency of canal, the optimal regulation model is built and the water transfer schemes for 2020 and 2025 are determined.

\section{Schedulable water volume analysis}

Through the balance analysis of supply and demand in the study area, the total amount of water shortage in different planning years for the four cities under different guarantee rates is obtained, and the water supply indicators (Yellow River water, Yangtze River water) of the four cities are considered to determine the schedulable water volume.

\subsection{Balance analysis of water supply and demand}

There are many types of water sources in the four cities of the study area, including surface water, groundwater, unconventional water sources (reclaimed water, rainwater harvesting, seawater desalination, etc.), as well as foreign water (Yellow River water and Yangtze River water). Water users include living, production and ecology. Therefore, in order to better achieve water transfer, water balance analysis of local water resources is required in different planning years.

\subsubsection{Available water supply}

The water supply sources in the water receiving area 
can be divided into surface water source, groundwater source, unconventional water source and foreign water. Analysis of available water supply of surface water and groundwater is based on the series data from 1995 to 2014. Using the Pearson III curve, the amount of water under different frequencies is determined. Taking into account the water conservancy project and water resource utilization rate in the water receiving area, the available water volume is further determined ${ }^{[9]}$. The reclaimed water, rainwater and seawater in unconventional source is predicted according to their utilization situation. The available water supply of foreign water is determined according to the index of foreign water in each city which are form the Shandong Provincial Development Planning Commission document ${ }^{[10]}$.

\subsubsection{Water demand}

The forecast of water demand in the water receiving area mainly adopts the quantitative forecasting method. In this paper, the quota method and trend method are main method ${ }^{[11-12]}$. The forecast of water demand includes domestic water demand, production water demand and ecological environment water demand. The domestic water demand is determined by predicting the population of the planned year. The production water demand includes industry and agriculture water demand. The industrial water demand is determined by predicting the annual industrial output value and water consumption. The agricultural water demand is determined by the farmland actual irrigated area and the irrigation quota. The ecological water with ecological water use and urban public water use is predicated by trend analysis.

\subsubsection{Balance analysis of water supply and demand}

According to the forecast results of water demand and water supply under each guarantee rate, the balance analysis of water supply and demand is carried out for the different water source in the planning year of the four cities respectively ${ }^{[13]}$. The analysis results are shown in Table 1.

Table 1 The balance analysis of water supply and demand of four cities $\left(10^{4} \mathrm{~m}^{3}\right)$

\begin{tabular}{lcccc}
\hline \multirow{2}{*}{$\begin{array}{l}\text { Planning } \\
\text { year }\end{array}$} & City & \multicolumn{3}{c}{ Water shortage under different guarantee rates } \\
\cline { 3 - 5 } & & 72708.68 & $75 \%$ & $95 \%$ \\
\hline \multirow{2}{*}{2020} & Weifang & 73643.34 & 85834.18 & 92431.68 \\
& Qingdao & 17802.82 & 73768.01 & 73829.68 \\
& Yantai & 6273.62 & 28794.92 & 55746.92 \\
& Weihai & 88156.66 & 22018.24 & 36442.38 \\
\hline \multirow{2}{*}{2025} & Weifang & 98708.08 & 101282.16 & 107879.66 \\
& Qingdao & 43881.71 & 98832.75 & 98894.42 \\
& Yantai & 22143.15 & 54873.81 & 81825.81 \\
& Weihai & 37887.76 & 52311.91 \\
\hline
\end{tabular}

\subsection{Water diversion indicator}

The water supply indicators of the four cities in the study area are shown in Table $2^{[10]}$. The water diversion indicator does not reflect the principle of increase or decreases based on water in abundance or depletion. Therefore, in this study, the water diversion indicators of Yellow River or Yangtze River under different guarantee rates remain unchanged in the different planning years of each city.

Table 2 The water diversion indicator of four cities in the study area $\left(10^{4} \mathrm{~m}^{3}\right)$

\begin{tabular}{cccc}
\hline area & Yellow River & Yangtze River & total \\
\hline Weifang & 30700 & 10000 & 40700 \\
Qingdao & 23300 & 13000 & 36300 \\
Yantai & 13700 & 9650 & 23350 \\
Weihai & 5200 & 5000 & 10200 \\
\hline
\end{tabular}

\subsection{Schedulable water quantity}

According to the balance analysis of water supply and demand, the water shortage under different guarantee rates in different cities is determined, and the water diversion indicators of the four cities are considered. Because the water shortage is higher than the water diversion indicator under the different guarantee rates of the four cities, the four cities can conduct water dispatch according to the water diversion index. The schedulable water volumes of four cities are carried on 
by the water diversion indicators of the four cities.

\section{Water resources optimal regulation}

\subsection{Water transfer project generalization}

There are 20 bleeders in the actual water transfer operation of the study area. Among them, the bleeders from 1to 7 are responsible for the water supply of Weifang City, the No.8 and No.9 bleeders are in charge of the water supply of Qingdao City, and the bleeders from 10 to 19 are responsible for the water supply of Yantai City. The No. 20 bleeder is for the water supply of Weihai City. The generalized diagram of the water transfer system is shown in Figure $2^{[14]}$.

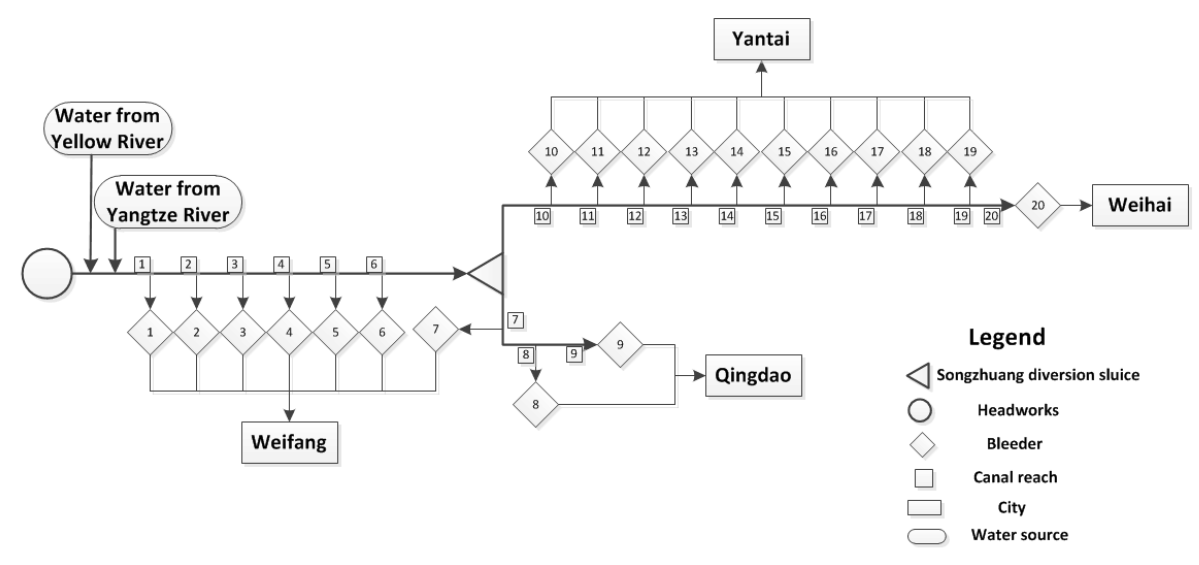

Figure 2 The generalized diagram of the water transfer system of all bleeders is the smallest ${ }^{[14]}$. The objective function

\subsection{Optimal regulation model construction}

(1) Determine the scheduling period

Considering the calendar year scheduling situation of the Jiaodong water transfer project and the full utilization of the configured water volume, the model will perform the full-time scheduling of the configured water volume throughout the year. The starting and ending time of the scheduling period is from October of the current year to September of the following year.

(2) Determine the scheduling time interval

Considering the distance from the headworks to each bleeder, it is determined that the scheduling time interval of the Jiaodong water transfer project is monthly, and the scheduling is performed on a monthly basis. Let the scheduling time interval be $i$, $i=1,2, \ldots, 12$.

(3) Determine decision variables

The decision variable is the monthly regulation water volume of each bleeder. Let the decision variable be $q_{1, j}$, that is, $q_{1, j}$ is the amount of monthly regulation water volume for the $j$-th bleeder in the $i$-th the scheduling time interval. Where $i$ is the scheduling time interval, and $\mathrm{j}$ is the bleeder, $i=1,2, \ldots, 12$; $j=1,2, \ldots, 20$.

(4) The objective function

The goal of optimal regulation is to minimize total water shortage for all bleeders. So the optimal regulation objective function is that the water shortage is:

$$
\min f=\sum_{i} \sum_{j}
$$

Where $\mathrm{f}$ is the total water shortage of all bleeders $\left(10^{4} \mathrm{~m}^{3}\right) ; d_{\mathrm{i}, \mathrm{j}}$ is the water demand of the $j$-th bleeder of the $i$-th month $\left(10^{4} \mathrm{~m}^{3}\right)$.

(5) Restrictions

(1) Schedulable water quantity constraint

$$
\sum_{i} \sum_{j} S_{i, j} \leq Q_{t}
$$

Where $s_{1}$ is the amount of water $\left(10^{4} \mathrm{~m}^{3}\right)$ from headworks to the $j$-th bleeder of the $i$-th month; $Q$ is the schedulable water quantity $\left(10^{4} \mathrm{~m}^{3}\right)$ of Weifang, Qingdao, Yantai and Weihai, respectively; $t=1,2,3,4$.

Because there is a loss of water delivery during water scheduling, there are:

$$
S_{i, j}=\frac{q_{i, j}}{\beta_{i, j}}
$$

Where $\beta_{\mathrm{i}, \text { is }}$ is the water delivery efficiency from the headworks to the $j$-th bleeder in the $i$-th month.

(2)Water demand constraint for each bleeder

$$
q_{i, j} \leq d_{i, j}
$$

(3) Minimum water demand constraint for each bleeder

In order to meet the water demand requirement, 
the water supply must be no less than the basic domestic water consumption, that is, the minimum water demand of each bleeder.

$\min q_{i, j} \leq q_{i, j}$

Where min $q_{1}$,is the minimum water supply for the $j$-th bleeder of the $i$ - $t$ h month $;\left(10^{4} \mathrm{~m}^{3}\right)$.

(4) Canal water balance constraint

According to the canal water balance principle, constraint equation is gotten in different canal reach. It is as follows:

$$
W_{i, j+1}=W_{i, j} *
$$

Where $W_{\mathrm{i}, \mathrm{j}}, W_{\mathrm{i}, \mathrm{j}+1}$ are the input water volume of the $i$-th month in $j$-th and $j+1$-th canal reach, respectively $\left(10^{4} \mathrm{~m}^{3}\right) ; \quad \alpha_{\mathrm{i}, j}$ is the water delivery efficiency of the $j$-th canal reach in the $i$-th month. As there is Songzhuang water diversion sluice among the 6th canal reach, the7th canal reach and the 10th canal reach. The canal water balance constraint of the 7th canal reach and the 10th canal reach are as follows:

$$
\begin{aligned}
& w_{i, 7}=\left(w_{i, 6} * \alpha_{i, 6}-\right. \\
& w_{i, 10}=\left(w_{i, 6} * \alpha_{i, 6}-\right.
\end{aligned}
$$

Where $k$ is the water delivery coefficient to Yantai and Weihai, $0 \leq \mathrm{k} \leq \frac{22}{29}$.

(5)Water supply capacity constraints for each canal reach

$$
W_{i, j} \leq W_{i, j}^{\text {设 }}
$$

Where $W^{i n}{ }_{i, j}$ is the water delivery capacity of the $j$-th canal reach in the $i$-th month $\left(10^{4} \mathrm{~m}^{3}\right)$.

(6)Non-negative constrains

$$
\begin{aligned}
q_{i j} & \geq 0 \\
s_{i j} & \geq 0 \\
W_{i j} & \geq 0 \\
d_{i j} & \geq 0 \\
Q_{t} & \geq 0
\end{aligned}
$$

\subsection{Optimal regulation scheme determination}

The optimal regulation schemes are obtained by

\begin{tabular}{|c|c|c|c|c|c|c|c|c|c|c|c|c|c|c|c|}
\hline \multirow{2}{*}{$\begin{array}{c}\text { Planni } \\
\text { ng } \\
\text { year }\end{array}$} & \multirow{2}{*}{$\begin{array}{l}\text { Guara } \\
\text { ntee } \\
\text { rate }\end{array}$} & \multirow{2}{*}{$\begin{array}{l}\text { Water } \\
\text { source }\end{array}$} & \multicolumn{12}{|c|}{ Monthly water distribution $\left(10^{4} \mathrm{~m}^{3}\right)$} & \multirow{2}{*}{$\begin{array}{l}\text { Unscheduled } \\
\text { water volume } \\
\text { - } / \text { million } \mathrm{m}^{3}\end{array}$} \\
\hline & & & October & November & December & January & February & March & April & May & June & July & August & September & \\
\hline \multirow{6}{*}{2020} & \multirow{3}{*}{$50 \%$} & $\begin{array}{l}\text { Yellow } \\
\text { River }\end{array}$ & 6191.5 & 5991.8 & 6191.5 & 6191.5 & 5592.3 & 6191.5 & 5991.8 & 6191.5 & 5991.8 & 6191.5 & 6191.5 & 5991.8 & 0 \\
\hline & & $\begin{array}{c}\text { Yellow } \\
\text { River|Yang } \\
\text { tze }\end{array}$ & 9374.4 & 9072 & 9374.4 & 9374.4 & 8467.2 & 9374.4 & 9072 & 9374.4 & 9072 & 9374.4 & 9374.4 & 9072 & 174 \\
\hline & & $\begin{array}{c}\text { Yellow } \\
\text { River }\end{array}$ & 6191.5 & 5991.8 & 6191.5 & 6191.5 & 5592.3 & 6191.5 & 5991.8 & 6191.5 & 5991.8 & 6191.5 & 6191.5 & 5991.8 & 0 \\
\hline & \multirow[t]{2}{*}{$75 \%$} & $\begin{array}{c}\text { Yellow } \\
\text { River|Yang } \\
\text { tze }\end{array}$ & 9374.4 & 9072 & 9374.4 & 9374.4 & 8467.2 & 9374.4 & 9072 & 9374.4 & 9072 & 9374.4 & 9374.4 & 9072 & 174 \\
\hline & & $\begin{array}{l}\text { Yellow } \\
\text { River }\end{array}$ & 6191.5 & 5991.8 & 6191.5 & 6191.5 & 5592.3 & 6191.5 & 5991.8 & 6191.5 & 5991.8 & 6191.5 & 6191.5 & 5991.8 & 0 \\
\hline & \multirow[t]{2}{*}{$95 \%$} & $\begin{array}{c}\text { Yellow } \\
\text { RiveriYang } \\
\text { tze }\end{array}$ & 9374.4 & 9072 & 9374.4 & 9374.4 & 8467.2 & 9374.4 & 9072 & 9374.4 & 9072 & 9374.4 & 9374.4 & 9072 & 174 \\
\hline \multirow{4}{*}{2025} & & $\begin{array}{c}\text { Yellow } \\
\text { River }\end{array}$ & 6191.5 & 5991.8 & 6191.5 & 6191.5 & 5592.3 & 6191.5 & 5991.8 & 6191.5 & 5991.8 & 6191.5 & 6191.5 & 5991.8 & 0 \\
\hline & \multirow[t]{2}{*}{$50 \%$} & $\begin{array}{c}\text { Yellow } \\
\text { RiveriYang } \\
\text { tze }\end{array}$ & 9374.4 & 9072 & 9374.4 & 9374.4 & 8467.2 & 9374.4 & 9072 & 9374.4 & 9072 & 9374.4 & 9374.4 & 9072 & 174 \\
\hline & & $\begin{array}{l}\text { Yellow } \\
\text { River }\end{array}$ & 6191.5 & 5991.8 & 6191.5 & 6191.5 & 5592.3 & 6191.5 & 5991.8 & 6191.5 & 5991.8 & 6191.5 & 6191.5 & 5991.8 & 0 \\
\hline & $75 \%$ & $\begin{array}{c}\text { Yellow } \\
\text { River|Yang } \\
\text { tze }\end{array}$ & 9374.4 & 9072 & 9374.4 & 9374.4 & 8467.2 & 9374.4 & 9072 & 9374.4 & 9072 & 9374.4 & 9374.4 & 9072 & 174 \\
\hline
\end{tabular}
solution model using MATLAB programming. There are 12 kinds of regulation schemes in the four cities under different water sources, different planning years and different guarantee rates. The monthly water regulation schemes of all bleeders for four cities are shown in Table 3. The scheduling result analysis is shown in Table 4.

Table 3 Total water regulation of each bleeder for four cities 


\begin{tabular}{ccccccccccccccccccc}
\hline & $\begin{array}{c}\text { Yellow } \\
\text { River }\end{array}$ & 6191.5 & 5991.8 & 6191.5 & 6191.5 & 5592.3 & 6191.5 & 5991.8 & 6191.5 & 5991.8 & 6191.5 & 6191.5 & 5991.8 & 0 & \\
$95 \%$ & $\begin{array}{c}\text { Yellow } \\
\text { River|Yang } \\
\text { tze }\end{array}$ & 9374.4 & 9072 & 9374.4 & 9374.4 & 8467.2 & 9374.4 & 9072 & 9374.4 & 9072 & 9374.4 & 9374.4 & 9072 & 174 \\
\hline
\end{tabular}

Table 4 The scheduling result analysis of 12 scheduling schemes

\begin{tabular}{|c|c|c|c|c|c|c|}
\hline $\begin{array}{l}\text { Water } \\
\text { source }\end{array}$ & $\begin{array}{l}\text { Planning } \\
\text { level year }\end{array}$ & $\begin{array}{l}\text { Guarantee } \\
\text { rate }\end{array}$ & $\begin{array}{l}\text { Scheduling } \\
\text { period }\end{array}$ & $\begin{array}{c}\text { Total water } \\
\text { shortage of } \\
\text { all bleeders } \\
\left(10^{4} \mathrm{~m}^{3}\right)\end{array}$ & $\begin{array}{c}\text { Total } \\
\text { scheduling } \\
\text { water of all } \\
\text { bleeders } \\
\left(10^{4} \mathrm{~m} 3\right)\end{array}$ & $\begin{array}{c}\text { Water } \\
\text { shortage } \\
\text { rate after } \\
\text { regulation } \\
(\%)\end{array}$ \\
\hline \multirow{6}{*}{$\begin{array}{l}\text { Yellow } \\
\text { River }\end{array}$} & \multirow{3}{*}{2020} & $50 \%$ & annual & 170428.5 & 72900 & 24.19 \\
\hline & & $75 \%$ & annual & 210415.4 & 72900 & 32.54 \\
\hline & & $95 \%$ & annual & 258450.7 & 72900 & 42.52 \\
\hline & \multirow{3}{*}{2025} & $50 \%$ & annual & 252889.6 & 72900 & 34.74 \\
\hline & & $75 \%$ & annual & 292876.5 & 72900 & 41.77 \\
\hline & & $95 \%$ & annual & 340911.8 & 72900 & 50.18 \\
\hline \multirow{6}{*}{$\begin{array}{c}\text { Yellow } \\
\text { RiverlYangt } \\
\text { ze }\end{array}$} & \multirow{3}{*}{2020} & $50 \%$ & annual & 170428.5 & 110376 & 19.92 \\
\hline & & $75 \%$ & annual & 210415.4 & 110376 & 27.79 \\
\hline & & $95 \%$ & annual & 258450.7 & 110376 & 36.63 \\
\hline & \multirow{3}{*}{2025} & $50 \%$ & annual & 252889.6 & 110376 & 30.80 \\
\hline & & $75 \%$ & annual & 292876.5 & 110376 & 37.78 \\
\hline & & $95 \%$ & annual & 340911.8 & 110376 & 45.22 \\
\hline
\end{tabular}

It is known from Table 4 that there are 12 kinds of scheduling schemes alleviated after water resources optimal regulation. Only considering the Yellow River water, the water shortage is decreased by 729 million $\mathrm{m}^{3}$. In the planning year of 2020 , the water shortage rate under each guarantee rate is decreased by $11.08 \%$, $11.00 \%$ and $10.96 \%$, respectively. In the planning year 2025 , the water shortage rate under each guarantee rate is decreased by $9.33 \%, 9.72 \%$ and $9.23 \%$,respectively. Both considering the Yellow River water and the Yangtze River water, the water shortage is reduced by 110.376 million $\mathrm{m}^{3}$. In the planning year of 2020, the water shortage rate under each guarantee rate is reduced by $15.35 \%, 15.75 \%$ and $16.85 \%$, respectively. In the planning year 2025, the water shortage rate under each guarantee rate is reduced by $13.27 \%, 13.26 \%$ and $14.19 \%$, respectively. Through comparative analysis, when the Yellow River water and the Yangtze River water are optimal regulation at the same time, it is better to alleviate the contradiction between supply and demand in the water receiving area. It ensures the coordinated development of the social economy and the ecological environment

\section{Conclusion}

( 1 ) Water resources optimal regulation has significantly reduced the water shortage rate in the four cities, which can effectively alleviate the serious water supply and demand contradiction in the Jiaodong area and provide regular scheduling support for the Jiaodong water transfer project.

(2) Although the transfer of foreign water can alleviate the shortage of water resources in the Jiaodong area, due to the limited water delivery capacity of the water transfer project, the overall water demand requirements of the region cannot be met. For the sustainable development of the Jiaodong area, the scale of the water transfer project needs to be expanded.

(3) Due to the consideration of minimizing the shortage of water resources in the study area, this paper only discusses the scheduling plan with the scheduling period as the whole year, and does not calculate the situation that the scheduling period is not full year. However, according to the actual operation of the water transfer project, the engineering maintenance period is usually required, and the next step is to discuss the non-annual scheduling.

(4) Due to the lack of information on the water supply area of each of the four cities, this paper uses the generalization calculation when calculating the minimum water demand of each bleeder, so that there is a certain deviation between the scheduling result and the actual demand. In the next step, with the improvement of the data, the scheduling result is further corrected, so that the scheduling scheme better satisfy actual needs.

\section{Acknowledgements}

This work was supported by (1) the project "Study on optimal allocation of water resources and decision 
support system for inter-basin water transfer project" (Project No: 31410005071701), and (2) the project "Flash Flood Disaster Prevention and Control Technology Application Research in Shandong Province" (Project No: SZJSYY-YJ201501, SZJSYY-YJ201502).

Authors thank anonymous reviewers for their constructive and helpful feedback on this manuscript.

\section{references}

1. Willis R,William W-G Yeh. Ground water system planning and management New jersey Prentice Hall,1987,21 23.

2. Afzaljavaid Noble David H. Optimization model for alternative use of different quality irrigation waters[J].Journal of Irrigation and Drainage Engineering,1992,118(2):218 227.

3. Chen Long. Study on the optimal attemper of water quantity and water quality of landscaping riverway multiple water resources [D]. Tianjin University, 2008.

4. Qi Xuebin, Pang Hongbin. et al. Present situation and tendency of conjunctive ground water and surface water management $[\mathrm{J}]$. Advanced in Water Science, 1999,(3):89 94.

5. Wang Hongjiang. Comprehensive management for water resources of interbasin water transfers [D]. Hohai University, 2003.

6. Pan Linggang, Wang Zhengzhong, Liu Jiliang. Water resource optimal regulation based on multi-objective programming method [J].Yellow River, 2011, 33(3): 49-50.

7. Yang Kan, Liu Yunbo. System decomposition-coordination macro-decision method for reservoirs based on multi-objective analysis [J]. Advanced in Water Science, 2001, 12(2): 232-236.

8. Zhang Zeyu, Wang Jinshan, et al. Studies on water system connecting model of Blue Economic Zone in Shandong Peninsula $[\mathrm{J}]$, China Water Resources, 2015, 8:43-45.

9. Jiang Xuguang. Study on water resources management of interbasin water transfer system [D].Tianjin University, 2008.

10. RenYanfei, Zhang Linbo. System analysis method of water resources and the application of optimal allocation of water resources[J].Water Conservancy Science and Technology and Economy,2006,12(10):695-696.

11. Song Sulin. Water resources optimal allocation and simulation of spring discharge on Jinan center urban [D].Shandong University, 2010.

12. Liu Linlin, Cao Shengle, Yu Cuisong, et al. Research on determination of the control index of total water use [J]. South-to-North Water Transfers and Water Science \& Technology, 2013,5(11):1672-1683.
13. Zhang Kaihui, Wang Haofang, et al. Study on optimal allocation of inter-basin water transfer project in Jiaodong area [J]. South-to-North Water Transfers and Water Science \& Technology, 2018,16 (2):100-107.

14. Yang Jingling, Wang Haofang, et al. Research on water resources optimal regulation of Jiaodong water diversion project[J]. Yellow River, 2018,40(05),58-62. 